\title{
Light harvesting in silicon (111) surfaces using covalently attached protoporphyrin IX dyes
}

\author{
Nicholas Alderman,,${ }^{\mathrm{a}, \mathrm{b}, \mathrm{b},{ }^{*}}$ Lefteris Danos, ${ }^{\mathrm{c},{ }^{*}}$ Liping Fang, ${ }^{\mathrm{d}}$ Martin C. Grossel, ${ }^{\mathrm{b}}$ and Tom Markvart ${ }^{\mathrm{a}, \mathrm{e}}$
}

a Solar Energy Laboratory, Faculty of Engineering and the Environment, University of Southampton, Southampton, SO17 1BJ, UK.

${ }^{\mathrm{b}}$ School of Chemistry, Faculty of Natural and Environmental Sciences, University of Southampton, Southampton, SO17 1BJ, UK.

${ }^{\mathrm{c}}$ Department of Chemistry, Energy Lancaster, Lancaster University, Lancaster, LA1 4YB, UK.

${ }^{\mathrm{d}}$ Institute of Materials, China Academy of Engineering Physics, Mianyang, 621900, P. R. China.

${ }^{\mathrm{e} C e n t r e}$ for Advanced Photovoltaics, Czech Technical University, 16627 Prague, Czech Republic.

${ }^{\natural}$ Current Address: Department of Chemistry, University of Ottawa, Ottawa K1N 6N5, Canada.

We report the photosensitization of crystalline silicon via energy transfer using covalently attached protoporphyrin IX (PpIX) derivative molecules at different distances via changing the diol linker to the surface. The diol linker molecule chain length was varied from 2 carbon to 10 carbon lengths in order to change the distance of PpIX to the $\operatorname{Si}(111)$ surface between $6 \AA$ and $18 \AA$. Fluorescence quenching as a function of the PpIX-Si surface distance showed a decrease in the fluorescence lifetime by almost two orders of magnitude at the closest separation. The experimental fluorescence lifetimes are explained theoretically by a classical Chance-Prock-Silbey model. At a separation below 2 nm, we observe for the first time, a Förster-like dipole-dipole energy transfer with a characteristic distance of $R_{\mathbf{0}}=2.7 \mathrm{~nm}$. 
The term "light harvesting" is often used to describe a process which enhances the absorption cross section of the photosynthetic reaction complex by energy transfer, often called Förster resonance energy transfer (FRET). ${ }^{1}$ It has been suggested on several occasions that a similar approach could be applied to semiconductors. ${ }^{2-5}$ In the case of an indirect band gap material such as crystalline silicon, photosensitisation has the potential to substantially enhance the photoexcitation rate for electron-hole pairs, resulting in significant savings in material, and bringing about an exciting new paradigm for future solar cells and other optoelectronic devices. ${ }^{6}$ Previous experimental studies have reported quenching of molecular fluorescence in proximity to silicon from evaporated dyes layers, ${ }^{4,5,7}$ quantum dots, ${ }^{8}$ Langmuir-Blodgett (LB) films ${ }^{9-12}$ or zeolite structures ${ }^{13}$ but at a greater distance of the emitter from the surface of silicon $(>2 \mathrm{~nm})$ than the work presented in this paper where we focus on emitter-surface separations of less than $2 \mathrm{~nm}$. The native oxide present on the surface of silicon then needs to be removed and the silicon surface subsequently functionalised. This results in a well-prepared surface with careful control of the emitter-surface distance. Viewed more generally, the modification of the silicon surface via the direct covalent attachment of organic molecules has seen an intense activity ${ }^{14-16}$ resulting in oxide free silicon surfaces (with molecules immobilised) with good stability and electronic (passivation) properties. Alkyl-modified silicon surfaces have received significant interest due to their potential applications in solar cells, ${ }^{17,18}$ microelectronics, ${ }^{19,20}$ biochemical sensing ${ }^{21,22}$ and catalysis. ${ }^{23}$

In the present letter we report what we believe is the first demonstration of energy transfer at a controlled sub nanometer separation between a chromophore and silicon, which can be unequivocally attributed to near-field dipole-dipole interaction. A dipolar emitter placed within a subwavelength distance from the silicon surface "sees" an increased density of states into which radiation can be emitted, on account of coupling directly to the trapped modes in silicon via the evanescent field. Sometimes called "photon tunnelling", this mechanism explains well the increase of quenching rate at dipole separations of the order of a few tens of nanometers. ${ }^{24}$ In contrast, the interaction at emitter-surface separations of the order of $1 \mathrm{~nm}$ which are under investigation in this paper is dominated by the near field interaction between the emitter dipole moment and the transition dipole moment of the electron-hole pair excited in silicon. This interaction is similar to the near field dipole interaction between molecules which gives rise to the Förster energy transfer. Also known resonance energy transfer, this mechanism is generally accepted as underpinning the light harvesting energy collection in photosynthesis. 


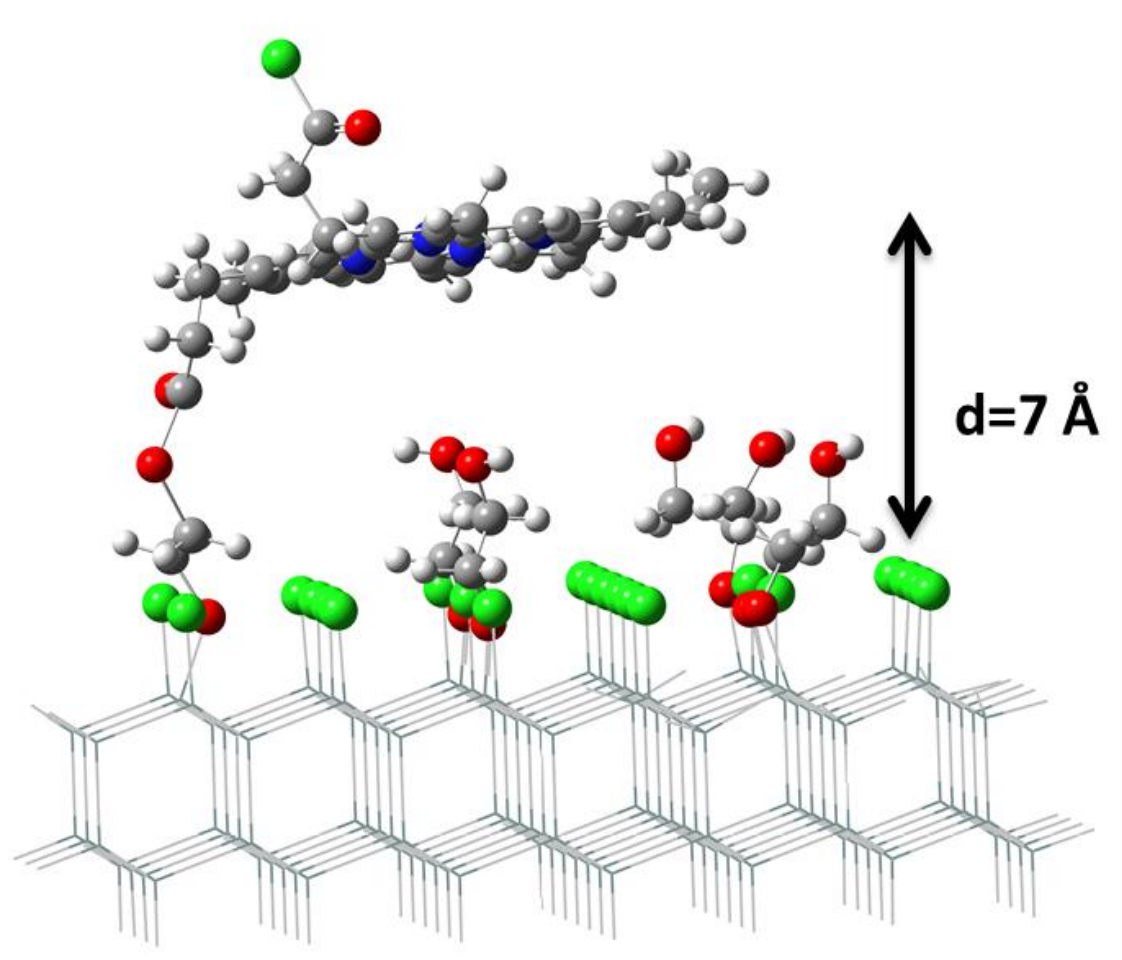

Fig. 1 A molecular model of the silicon (111) surface with diols and a PpIX molecule covalently attached.

By changing the distance from the dye to silicon via the length of a linker molecule, allows the dependence of this energy transfer from chromophore to semiconductor to be investigated in detail, and to separate the Förster-like energy transfer from photon tunnelling through the evanescent field.

The attachment of porphyrins to silicon surfaces has been well documented ${ }^{25,26}$ and perhaps the closest example found for sensitizing silicon is reported in ref; ${ }^{27}$ simpler experiments report the attachment of benzene or anthracene terminal groups ${ }^{28}$ to a silicon alkyl monolayer by an esterification reaction, resulting in coverage of at least $70 \%$. For the experiments performed in this paper, Protoporphyrin IX was chosen due to the commercial availability, ease of functionalisation and shifting of the absorption and emission maxima by coordination with metal ions. An example of a molecular model of a silicon (111) surface with ethane-diol linkers and a PpIX molecule attached is shown in Fig. 1. The presence of the large pi-ring will most likely force the molecule to adopt a parallel orientation with respect to the surface of silicon. The first step towards attachment of PpIX was the addition of the appropriate diol linker (Table S1, ESI $\dagger$ ) on the chlorine-terminated $\operatorname{Si}(111)$ surface (Scheme 1). 


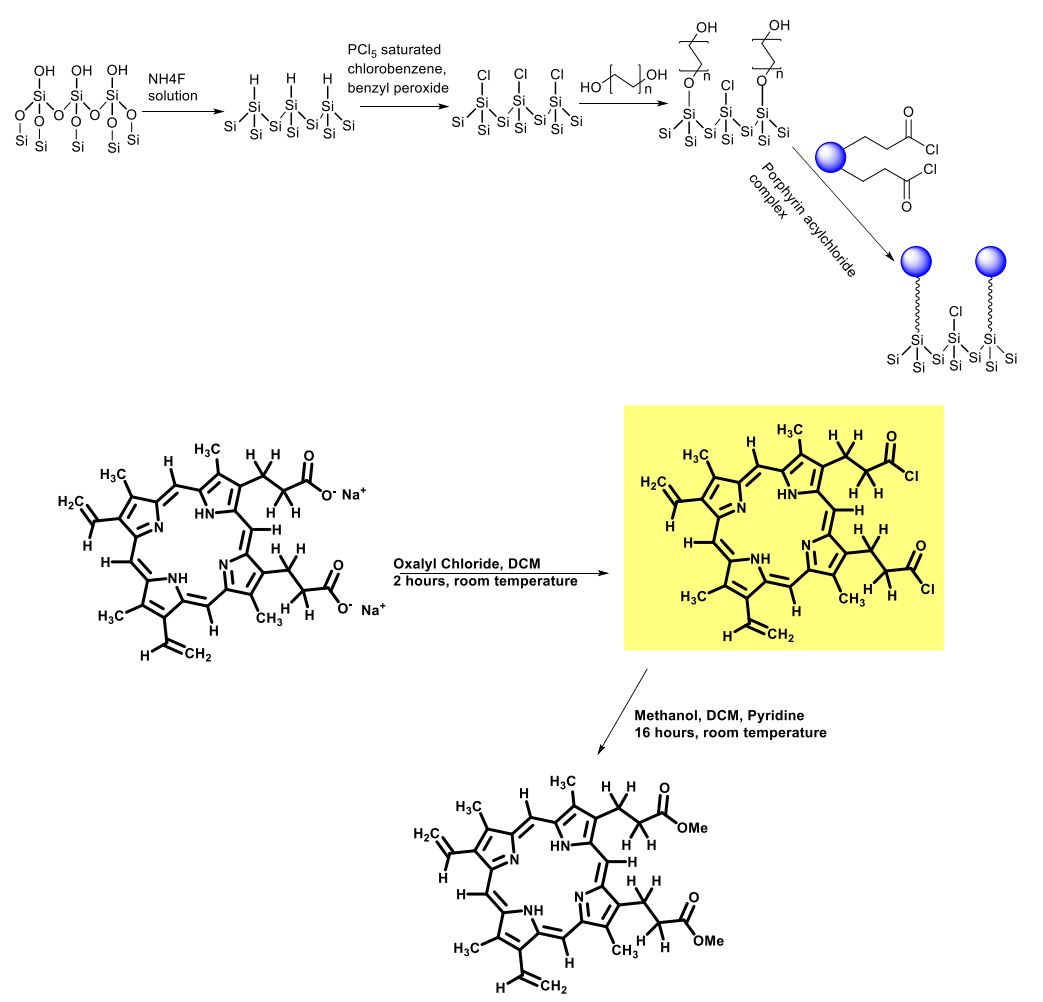

Scheme 1 Synthesis and attachment of the Protoporphyrin IX acyl chloride (PpIX-Cl) to the Si(111) surface.

By adding a small amount of base (such as pyridine), an increase in the uniformity of the siloxane monolayer is observed as well as a reduction in the required reaction temperature. FTIR measurements on the resulting alcohol-terminated $\mathrm{Si}(111)$ surfaces confirmed the formation of the required monolayer, allowing subsequent functionalization of the alcohol chains (Fig. S4, ESI $\dagger$ ). It was found empirically that to attach PpIX to the modified silicon surface successfully, pyridine should be added to the solution in order to catalyse and reduce the reaction temperature between the porphyrin and alcohol surface. This allowed a more gentle heating temperature of $80^{\circ} \mathrm{C}$, reducing the chance of porphyrin decomposition. The resulting silicon surfaces with PpIX molecules attached were then washed with DCM to remove any physisorbed porphyrin, and allow further characterisation with FT-IR, XPS and fluorescence measurements. Reflection FTIR and XPS verified the diol linker terminated $\mathrm{Si}(111)$ surfaces with estimated coverages up to $30 \%$. Subsequent functionalisation with PpIX molecules was verified with coverage of about 1$2 \%$. The infrared spectrum of a 1,4 butanediol treated silicon surface after functionalisation with PpIX is shown in Fig. S3 and S5 (ESI $\dagger$ ). The O-H peak of the functionalised surface is clearly visible, showing that unreacted alcohol groups remain. This is due to the much larger porphyrin group blocking unreacted surface sites. The various $\mathrm{C}-\mathrm{H}$ groups of the porphyrin are clearly 
visible in the spectrum, as well as the $\mathrm{CH}_{2}$ peak of the butanol-terminated surface and the ester $\mathrm{C}=\mathrm{O}$ peak (Fig. S5, ESI $\dagger)$.

The presence of the porphyrin was further confirmed from XPS data. The nitrogen 1s binding region showed three distinct nitrogen binding energies; one for iminic nitrogen, another for pyrrolic nitrogen, and finally a smaller peak for possible physisorbed nitrogen, (Fig. S6, ESI†). The two peaks in the nitrogen $1 \mathrm{~s}$ binding energy matched other literature data for porphyrins. ${ }^{28}$ Interestingly, a 1:1 ratio of the integrals of the pyrrolic and iminic nitrogen peaks is not obtained as would be expected. This could suggest that a proportion of the surface-attached porphyrin has bound a transition metal ion within the porphyrin ring, reducing the number of pyrrolic nitrogen atoms observed. This metal could be incorporated during the porphyrin processing steps, arising from trace metal impurities found in all solvents. To confirm the correct assignment of the physisorbed nitrogen, a nitrogen 1s XPS spectrum was obtained for a 1,4butanediol surface (Fig. S7, ESI†).

Variable Angle Spectroscopic Ellipsometry (VASE) measurement of the diol linker silicon surfaces and analysis confirmed the attachment of the diols linkers with different carbon chain lengths on the surface of silicon and were found in good agreement with DFT calculations (Table 1).

Table 1 Variable Angle Spectroscopic Ellipsometry analysis results for the different Diol linkers on Silicon with different carbon chain lengths

\begin{tabular}{clcc}
$\begin{array}{l}\text { Carbon } \\
\text { Chain } \\
\text { Length }\end{array}$ & \multicolumn{1}{c}{ Sample } & $\begin{array}{c}\text { Measured Thickness } \\
(\AA)\end{array}$ & $\begin{array}{c}\text { Calculated Thickness } \\
(\AA)\end{array}$ \\
\hline 2 & $\mathrm{Si}(111)-\mathrm{O}-\mathrm{CH}_{2}-\mathrm{CH}_{2}-\mathrm{OH}$ & $5.5 \pm 0.6$ & 6.0 \\
3 & $\mathrm{Si}(111)-\mathrm{O}-\mathrm{CH}_{2}-\mathrm{CH}_{2}-\mathrm{CH}_{2}-\mathrm{OH}$ & $9.5 \pm 0.6$ & 7.3 \\
4 & $\mathrm{Si}(111)-\mathrm{O}-\left(\mathrm{CH}_{2}-\mathrm{CH}_{2}\right)_{2}-\mathrm{OH}$ & $14.4 \pm 0.5$ & 8.6 \\
6 & $\mathrm{Si}(111)-\mathrm{O}-\left(\mathrm{CH}_{2}-\mathrm{CH}_{2}\right)_{3}-\mathrm{OH}$ & $15.0 \pm 0.4$ & 11.1 \\
8 & $\mathrm{Si}(111)-\mathrm{O}-\left(\mathrm{CH}_{2}-\mathrm{CH}_{2}\right)_{4}-\mathrm{OH}$ & $17.2 \pm 0.4$ & 13.6 \\
10 & $\mathrm{Si}(111)-\mathrm{O}-\left(\mathrm{CH}_{2}-\mathrm{CH}_{2}\right)_{5}-\mathrm{OH}$ & $18.5 \pm 0.4$ & 16.3 \\
\hline
\end{tabular}

The ellipsometric measurements were fitted to a simple Cauchy model (Fig S8, ESI $\dagger$ ). Examples of steady state fluorescence spectra obtained from PpIX-functionalised (propane, butane and decane diol linker) silicon surfaces are shown in Fig. S9 (ESI†). To confirm that the spectrum was indeed due to the attachment of the porphyrin, a fluorescence spectrum of a 1,2ethanenediol terminated only surface was also obtained and showed no fluorescence activity. All PpIX attached silicon surfaces with different linkers showed similar steady state spectra and 
only the intensity of emission changed. The spectra do not show the typical two peaks for a PpIX in solution (Dimethyl ester) ${ }^{29}$ occurring at $633 \mathrm{~nm}$ and $700 \mathrm{~nm}$ but instead show a broad emission peak starting from $610 \mathrm{~nm}$ to $800 \mathrm{~nm}$ with a maximum at $670 \mathrm{~nm}$. This is to be expected for the broad bandwidth $(16 \mathrm{~nm})$ employed in order to measure sub-monolayer dye coverages. Normalised fluorescence decay curves of the various porphyrin-linked surfaces, together with decay fits are shown in Fig. 2.

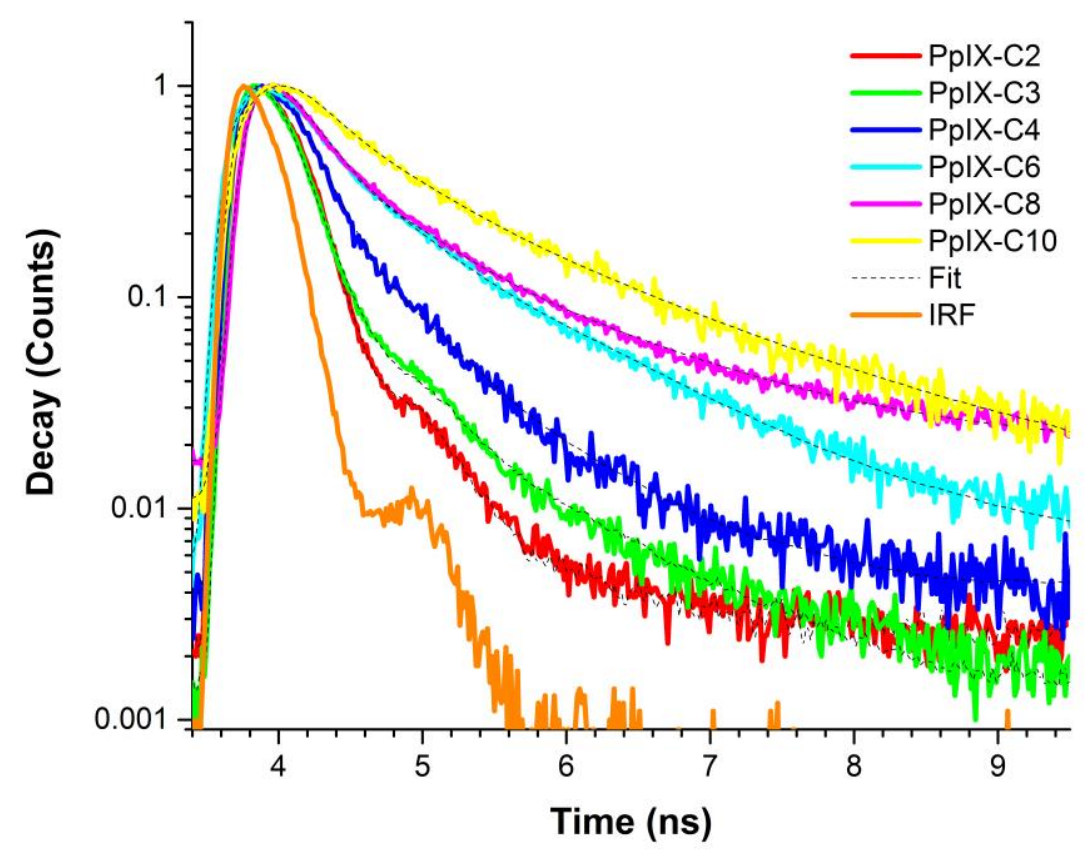

Fig. 2 The fluorescence decay curves of various chain-length terminated surfaces functionalised with protoporphyrin IX.

The fluorescence decay curves show that as the fluorophore is moved closer to the silicon surface, the fluorescence decay lifetimes become shorter indicating a greater degree of fluorescence quenching. The reason for the quenching of the fluorescence is likely to arise from energy transfer from the excited PpIX to silicon. As the distance between PpIX and the surface is reduced from $15 \AA$ down to $5 \AA$ the rate of energy transfer becomes greater and the fluorescence lifetime decay shortens significantly. When the chromophore-surface distance becomes very small (such as for the ethanediol-linked PpIX), the decay almost matches the profile of the laser pulse reaching the resolution limit of the instrument ( $250 \mathrm{ps})$. As the linker chain-length is increased, the fluorescence decay time increases, although the largest differences in decay rates were between those for different shorter linker groups (Table S2, ESI $\dagger$ ). 
To describe the fluorescence quenching we have modified the classical theory by Chance, Prock and Silbey ${ }^{30}$ (CPS) developed originally for the observation of fluorescence quenching of dye layers on the surface of metals. As can be seen in Table S2 (ESI $\dagger$ ), the fluorescence lifetime increases with increasing distance to the surface. The fluorescence lifetime change is considerable, changing by almost two orders of magnitude when moving from ethanediol to decanediol-terminated surfaces, and the PpIX-silicon separation decreases from just below $2 \mathrm{~nm}$ to $0.6 \mathrm{~nm}$. The fluorescence lifetime for the diol-linked PpIX-terminated surfaces is shown in Fig. 3. The red solid line in Fig. 3 was obtained by fitting the well-known CPS theory ${ }^{30}$ using a fluorescence quantum yield of 0.2 which was close to reported value in literature. ${ }^{31} \mathrm{We}$ assumed, in keeping with theoretical understanding of electron transition in porphyrins, that the electric transition dipole moment is oriented in the plane of the molecule, parallel to the silicon surface. Other orientations, however, could also be used with little difference observed (Fig. S10, ESI $\dagger$ ).

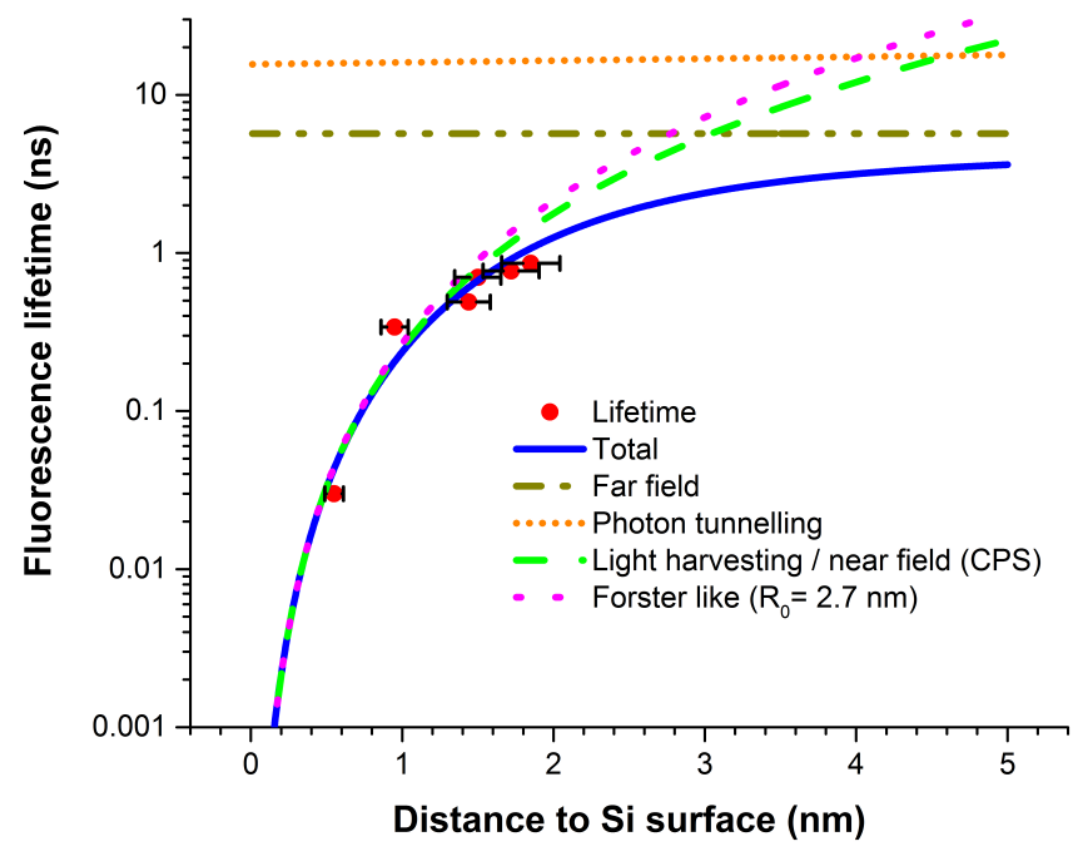

Fig. 3 The fluorescence lifetime for various diol linked porphyrin surfaces. Experimental points are fitted by Chance-Prock-Sibley theory (CPS, full blue line). Also shown, by dashed and dotted lines, are separate contributions from different mechanisms.

Fig. 3 shows different lifetime components for a dipole near the silicon surface, as modelled by the CPS theory. The far field contribution is simply the dipole emission in free space as modified by interference with a wave reflected from the surface. Photon tunnelling (studied in detail in ref. 16) is an optical effect describing energy transfer, through the evanescent field, from the 
excited molecular state directly to the photon states in silicon trapped by total internal reflection. Of principal interest is the near field component which corresponds to the interaction between the transition dipole moment at the molecule and at the excited electron-hole pair in silicon. The Förster-like energy transfer between an emitter dipole and an array of acceptors filling a semiinfinite half space is predicted to follow the distance dependence ${ }^{1}$

$$
\frac{1}{\tau}=\frac{1}{\tau_{o}}\left(\frac{R_{o}}{d}\right)^{3}
$$

where $\tau_{\mathrm{o}}$ is the fluorescence lifetime in the absence of silicon interface, $d$ is the chromophoresilicon separation and $R_{\mathrm{o}}$ is the equivalent of the Förster radius between molecules. We believe that the present work demonstrates for the first time, the Förster-like energy transfer between a molecule and semiconductor and allows the determination of the Förster radius $R_{\mathrm{o}}=2.7 \mathrm{~nm}$. Further work is needed to elucidate finer details of this interaction such as the role of direct and indirect transitions in the transfer ${ }^{2}$ or the importance of screening at this small dipole-dipole separation. ${ }^{6}$

In conclusion, we have successfully attached a porphyrin dye to the silicon (111) surface by a siloxane/alcohol technique, as confirmed by infrared spectroscopy, XPS and fluorescence spectroscopy. By using terminal dihydroxyalkanes as the linker chain we have prepared a

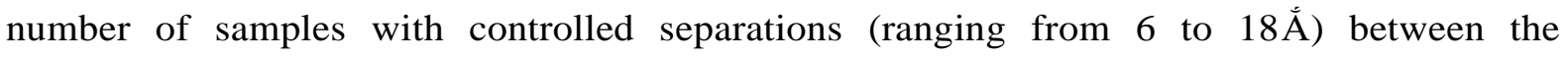
chromophore and the silicon surface. The silicon-chromophore separations determined by ellipsometry agree well with the calculated valued determined by DFT. The key quantity of interest - fluorescence quenching - agrees well with the predictions of the CPS model. In particular, at dipole separation from the silicon surface below $2 \mathrm{~nm}$, we have identified unequivocally the dominant role of Förster-like resonance energy transfer, with a "Förster radius" of $2.7 \mathrm{~nm}$. We believe that direct sensitisation of indirect bandgap semiconductors such as silicon has potentially a huge technological significance, turning, in effect, silicon into a direct-bandgap material.

This work was funded by the UK EPSRC SUPERGEN program "Photovoltaic materials for the 21st century" (Reference: EP/F029624/1 and EP/F029624/2). Centre for Advanced Photovoltaics is supported by Czech Ministry of Education, Youth and Sport. CZ.02.1.01/0.0/0.0/15_003/0000464. Liping Fang thanks for financial support from National Natural Science Foundation of China (item No. 61604138). We would like to thank Dr M. 
Coogan for helpful suggestions on the manuscript and Dr A. Kerridge for assistance with molecular modelling.

\section{Notes and references}

1 D. L. Andrews and A. A. Demidov, Eds., Resonance Energy Transfer, Joh Wiley \& Sons Ltd, 1999.

2 D. L. Dexter, J. Lumin., 1979, 18/19, 779.

3 T. Markvart, Prog. Quantum Electron., 2000, 24, 107-186.

4 P. M. Whitmore, A. P. Alivisatos and C. B. Harris, Phys. Rev. Lett., 1983, 50, 1092.

5 T. Hayashi, T. G. Castner and R. W. Boyd, Chem. Phys. Lett., 1983, 94, 461.

6 V. M. Agranovich, Y. N. Gartstein and M. Litinskaya, Chem. Rev., 2011, 111, 5179-214.

7 A. P. Alivisatos, M. F. Arndt, S. Efrima, D. H. Waldeck and C. B. Harris, J. Chem. Phys., 1987, 86, 6540.

8 M. T. Nimmo, L. M. Caillard, W. De Benedetti, H. M. Nguyen, O. Seitz, Y. N. Gartstein, Y. J. Chabal and A. V Malko, ACS Nano, 2013, 7, 3236-45.

9 M. I. Sluch, A. G. Vitukhnosky and M. C. Petty, Phys. Lett. A, 1995, 200, 61.

10 L. Danos, R. Greef and T. Markvart, Thin Solid Films, 2008, 516, 7251-7255.

11 L. Danos and T. Markvart, Chem. Phys. Lett., 2010, 490, 194-199.

12 L. Fang, N. Alderman, L. Danos and T. Markvart, Mater. Res. Innov., 2014, 18, 494-499.

13 S. Huber and G. Calzaferri, Chemphyschem, 2004, 5, 239-42.

14 J. M. Buriak, Chem. Rev., 2002, 102, 1271-308.

15 B. Fabre, Chem. Rev., 2016, 116, 4808-4849.

16 W. Peng, S. M. Rupich, N. Shafiq, Y. N. Gartstein, A. V. Malko and Y. J. Chabal, Chem. Rev., 2015, 115, 12764.

17 A. B. Sieval, C. L. Huisman, A. Schönecker, F. M. Schuurmans, A. S. H. van der Heide, A. Goossens, W. C. Sinke, H. Zuilhof and E. J. R. Sudhölter, J. Phys. Chem. B, 2003, 107, 68466852.

18 N. Alderman, L. Danos, M. C. Grossel and T. Markvart, RSC Adv., 2013, 3, 20125.

19 E. J. Faber, L. C. P. M. de Smet, W. Olthuis, H. Zuilhof, E. J. R. Sudhölter, P. Bergveld and A. van den Berg, Chemphyschem, 2005, 6, 2153-66.

20 L. Segev, A. Salomon, A. Natan, D. Cahen and L. Kronik, Phys. Rev. B, 2006, 74, 1-6.

21 F. Wei, Biosens. Bioelectron., 2003, 18, 1157-1163.

22 W. Cai, J. R. Peck, D. W. van der Weide and R. J. Hamers, Biosens. Bioelectron., 2004, 19, $1013-9$. 
23 S. Dutta, M. Perring, S. Barrett, M. Mitchell, P. J. A. Kenis and N. B. Bowden, Langmuir ACS J. surfaces colloids, 2006, 22, 2146-55.

24 L. Fang, K. S. Kiang, N. P. Alderman, L. Danos and T. Markvart, Opt. Express, 2015, 23, A1528-A1532.

25 M. Lu, B. Chen, T. He, Y. Li and J. M. Tour, Chem. Mater., 2007, 19, 4447-4453.

26 K. Padmaja, L. Wei, J. S. Lindsey and D. F. Bocian, J. Org. Chem., 2005, 70, 7972-7978.

27 X. Zhang, Y. Wen, Y. Li, G. Li, S. Du, H. Guo, L. Yang, L. Jiang, H. Gao and Y. Song, J. Phys. Chem. C, 2008, 112, 8288-8293.

28 B. Fabre, D. M. Bassani, C. K. Liang, D. Ray, F. Hui and P. Hapiot, J. Phys. Chem. C, 2011, 115, 14786-14796.

29 J. M. Dixon, M. Taniguchi and J. S. Lindsey, Photochem. Photobiol., 2007, 81, 212-213.

30 R. R. Chance, A. Prock and R. Silbey, in Advances in Chemical Physics, eds. I. Prigogine and S. A. Rice, Wiley, New York, 1978, p. 1.

31 G. I. Lozovaya, Z. Masinovsky and A. A. Sivashi, Orig. Life. Evol. Biosph., 1990, 20, 321330. 


\section{Electronic Supporting Information (ESI) for:}

\section{Light harvesting in silicon (111) surfaces using covalently attached protoporphyrin IX dyes}

Nicholas Alderman ${ }^{1,2 * a}$, Lefteris Danos ${ }^{3 *}$, Liping Fang ${ }^{4}$, Martin C. Grossel $^{2}$ and Tom Markvart ${ }^{1,5}$

${ }^{1}$ Solar Energy Laboratory, Faculty of Engineering and the Environment, University of Southampton, Southampton, SO17 1BJ, UK

${ }^{2}$ School of Chemistry, Faculty of Natural and Environmental Sciences, University of Southampton, Southampton, SO17 1BJ, UK

${ }^{3}$ Department of Chemistry, Energy Lancaster, Lancaster University, Lancaster, LA1 4YB, UK

${ }^{\natural}$ Current Address: Department of Chemistry, University of Ottawa, Ottawa K1N 6N5, Canada

${ }^{4}$ Institute of Materials, China Academy of Engineering Physics, Mianyang, 621900, P. R. China

${ }^{5}$ Centre for Advanced Photovoltaics, Czech Technical University, 16627 Prague, Czech Republic.

* Corresponding Author: nickalderman@gmail.com

* Corresponding Author: L.Danos@lancaster.ac.uk 


\section{Experimental Details}

Synthesis of 3,7,12,17-Tetramethyl-8,13-divinyl-2,18-porphinedipropoyl chloride: All porphyrin containing solutions were kept in darkness and under nitrogen. To a solution of protoporphyrin IX disodium salt $(250 \mathrm{mg})$ in dry DCM $(20 \mathrm{~mL}), 2.5 \mathrm{~mL}$ of a $2 \mathrm{M}$ solution of oxalyl chloride ( 0.7616 moles) was added and the solution stirred for 2 hours. After removal of the solvent under vacuum, the green powder was transferred to a glovebox for subsequent reactions.

To confirm the presence of the porphyrin acyl chloride, the product was reacted with methanol $(5 \mathrm{~mL})$ in DCM $(10 \mathrm{~mL})$, with the addition of pyridine $(1 \mathrm{~mL})$ for 16 hours at room temperature (Scheme 10.3). After removal of the solvent under vacuum, the red / purple solid was purified by column chromatography using a 1:10 methanol:DCM eluent. Two red compounds were obtained; the starting material and the di-methoxy porphyrin which was analysed. MS(ES-) m/z: 1181.6 $\left(\mathrm{M}_{2}{ }^{+}\right), 591.3\left(\mathrm{M}^{+}\right)$, 454.2, 259.1, 170.1. 1H NMR (300 MHz, $\left.\mathrm{CDCl}_{3}\right) \delta$ ppm: 3.11-3.24 $(4.37 \mathrm{H}, 2 x \mathrm{x}), 3.50-3.67(15.37 \mathrm{H}$, M), 4.25-4.35 (4.00 H, QN), 6.07-6.15 (2.03 H, T), 6.25-6.35 (1.89 H, T), 8.11-8.27 (2.07 H, M), 9.9110.18 (4.00 H, M). (Fig. S1)

Mass Spectroscopy : Data was obtained on a Micromass ZMD electrospray MS and analysed using the Remote Analyser system. Fig. S2 shows the mass spectrum of the methoxy ester porphyrin synthesised via the acyl chloride protoporphyrin IX (PpIX-Cl).

Synthesis of Functionalised Silicon Surfaces: The silicon sample (10.5 x 10.5mm squares, n-type, 25 $\left.\Omega \mathrm{cm}^{-1}, 500 \mu \mathrm{m}\right)$ was cleaned in a hydrogen peroxide in sulphuric acid (1:3, 45 minutes) solution, followed by a thorough rinse in de-ionised water. Once the sample had been thoroughly cleaned, the surface of the silicon was etched in semiconductor grade ammonium fluoride (degassed, 15 minutes) to remove the native oxide layer and hydrogen-terminate the surface. After drying under flowing nitrogen, the sample was passed into a nitrogen filled glovebox for functionalisation. The hydrogen-terminated silicon was immersed in a saturated solution of phosphorus pentachloride in chlorobenzene $\left(110^{\circ} \mathrm{C}, 1.5\right.$ hours) to which a few grains $(<1 \mathrm{mg})$ of benzyl peroxide were added as a radical initiator. The sample was then washed in chlorobenzene and the appropriate $1, X$ diol (where $\mathrm{X}=$ carbon chain length). The chlorinated wafer was then immersed in the appropriate diol $(10 \mathrm{~mL})$ with $1 \mathrm{~mL}$ of pyridine and heated to $110^{\circ} \mathrm{C}$ for 24 hours. The structures of the different diols and PpIX derivative attached on $\mathrm{Si}(111)$ surfaces are shown in Table S1. After allowing the solution to cool and washing with methanol, the protoporhyrin IX acyl chloride $(100 \mathrm{mg})$ in DCM $(10 \mathrm{~mL})$ was added in darkness with a few drops of pyridine at $80^{\circ} \mathrm{C}$ for 48 hours (Scheme 1). The sample was then sonicated with acetonitrile $(10 \times 5 \mathrm{~mL})$ and dried under nitrogen, yielding the required surface. 
Infrared Spectroscopy: Measurements were taken using a Bruker Tensor 27 spectrometer fitted with a liquid nitrogen cooled mercury-cadmium-telluride (MCT) detector and a variable angle reflection accessory with polariser (VEEMAX II, PIKE technologies). For the measurements of the functionalised silicon samples, the reflection angle for the measurements was set to $37^{\circ}$ with S-polarisation of the reflected beam; the scan count was set to 500 scans, with a resolution of $4 \mathrm{~cm}^{-1}$ in the scan region 500 $-4000 \mathrm{~cm}^{-1}$. For all samples, a background of the native oxide was recorded. In Fig. S3 to S5, the main bands visible at approximately $~ 3250 \mathrm{~cm}^{-1}$ correspond to the $\mathrm{O}-\mathrm{H}$ stretching vibration from the free diol linkers on the silicon surface. The bands at $\sim 3072 \mathrm{~cm}^{-1}$ and $\sim 3018 \mathrm{~cm}^{-1}$ corresponding to the vinyl H$\mathrm{C}(=\mathrm{C})$ stretching absorption and the $\sim 2970 \mathrm{~cm}^{-1}$ and $\sim 2946 \mathrm{~cm}^{-1}$ peaks correspond to the antisymmetric and symmetric alkyl C-H vibrations. In Fig. S5 the ester carbonyl stretch is shown for the 1,4 butanediol PpIX molecule on the silicon surface at $\sim 1740 \mathrm{~cm}^{-1}$. The observed splitting of almost equally intensity is due to the hydrogen bonding of adjacent vacant diol groups with the ester carbonyl group of the PpIX molecule. Our assignments are in agreement with previous reported literature on monolayers on porphyrins attached on silicon. ${ }^{1,2}$ The diol linker terminated $\mathrm{Si}(111)$ surfaces were estimated to have coverages up to $30 \%$. The coverage decreased as a function of increasing diol linker due to steric hindrance, in accordance to previous reports in the literature. ${ }^{3-5}$ Subsequent functionalisation with PpIX molecules was verified with coverage of about $1-2 \%$.

X-ray Photoelectron Spectroscopy: XPS measurements on the samples were performed on a Thermo Fisher ME17 Thetraprobe system with a monochromatic Al X-ray source, set to a $400 \mu \mathrm{m}$ spot size. The scan count was set to 500 scans for the nitrogen spectra. Deconvolution of the spectra was performed by fitting the data to multiple Gaussian bands, reducing the residual square to a minimum. High resolution X-ray photoelectron spectroscopy (XPS) confirms the presence of protoporphyrin IX attachment on the silicon surface. The high resolution N 1s spectrum of the PpIX terminated silicon surface with a 1,4 butanediol linker is shown in Fig. S6, and the best fit was obtained with a three peak fit. From the integrals for the pyrrolic (-NH-) at $\sim 400.6 \mathrm{eV}$ and iminic $(=\mathrm{N})$ at $\sim 398.7 \mathrm{eV}$ nitrogen peaks confirms that the PpIX molecules were attached on the surface in accordance with previous XPS spectra on porphyrins in the literature. ${ }^{2,6,7}$ It appears that some porphyrin groups have bound a metal atom. This is likely to have come from trace metal impurities present in the solvents used. The presence of the third peak N 1s at $\sim 403 \mathrm{eV}$ could be attributed to small amounts of physisorbed nitrogen or slight oxidation of the attached porphyrin molecule. A comparison of $\mathrm{N}$ 1s high resolution XPS spectra from a PpIX anchored silicon surface and a diol only linker silicon surface is shown in Fig. S7. To estimate the coverage of the porphyrin dye, the ratio of nitrogen to oxygen in XPS was used assuming that nitrogen signals were only obtained from the dye, and oxygen signals only from the diol linker. 
Quantum Mechanical Calculations: Density Functional Theory (DFT) calculations were carried out using the Gaussian 09 computational package employing the B3LYP exchange correlation energy functional and the 6-311G** basis set. The lengths of all the free molecules for this study were estimated from the optimised structures.

Variable Angle Spectroscopic Ellipsometry: The thickness of the organic thin film layers was measured with variable angle spectroscopic ellipsometry (VASE) from $250 \mathrm{~nm}$ to $1000 \mathrm{~nm}$ at three different incidence angles $\left(60^{\circ}, 65^{\circ}\right.$, and $\left.70^{\circ}\right)$ using a spectroscopic phase modulated ellipsometer $(\mathrm{M}$ 2000 V Automated Angle, J. A. Woollam Co., Inc.,USA). The data collected were analysed using a three-layer model (substrate/monolayer/air) using silicon for the substrate and a Cauchy model for the optical properties of the monolayer. The fitting of the ellipsometry parameters has followed standard procedures that have widely been reported in the literature for similar samples with organic monolayers attached on silicon surfaces. ${ }^{8-11}$ The refractive index of the organic monolayer was restricted between $1.45-1.60(550-1000 \mathrm{~nm})$, which is a typical value estimated for similar organic monolayers previously reported in the literature. ${ }^{12-14}$ The $\mathrm{Si}-\mathrm{H}$ bare substrate was used as a reference and also to estimate the roughness of the surface. Multiple readings (on three different spots) were taken from each sample and averaged over all consistent measurements in order to minimise errors in the thickness measurements. There was no significant difference observed in the estimated organic layer thickness of the samples between the Protoporphyrin IX attached samples and diol linker only surfaces. The low coverage of the attached PpIX molecules on the silicon surface (1-2\%) did not gave appreciable change in the measurement of the thickness within the error of the measurement. In our case the angle of the monolayer to the surface does not affect the thickness within the $10 \%$ error that we have reported. Examples of ellipsometry model fits are shown in Fig. S8.

Time-Resolved Emission Spectra and Decays: Time-resolved emission spectra and decay measurements were carried out using time correlated single photon counting (TCSPC) setup on a FluoTime 200 (PicoQuant GmbH) system fitted with a $445 \mathrm{~nm}$ laser (LDH-P-C-445B, PicoQuant $\mathrm{GmbH}$ ) with a variable repetition frequency range from $10-80 \mathrm{MHz}$ driven, allowing a time domain range 12-100 ns for the fluorescence decay. The setup is equipped with a PicoHarp300 TCSPC board (PicoQuant $\mathrm{GmbH}$ ) and a Hamamatsu photomultiplier (PMA-192) with a spectral range from $300 \mathrm{~nm}$ to $900 \mathrm{~nm}$. The emission from the samples was collected at right angles to the excitation laser beam at $670 \mathrm{~nm}$ with a spectral bandwidth of $16 \mathrm{~nm}$. The full width half maximum (FWHM) of the system's instrument response function (IRF) was 175 ps. The fluorescence decay curves were analysed using the FluoFit software (PicoQuant GmbH, version 4.6.1) based on two-exponential models which involves an iterative re-convolution process. ${ }^{15}$ The quality of the fits was assessed by the value of the reduced $\chi^{2}$ 
value (a value of less than 1.2 for an acceptable fit), and a visual inspection of the distribution of the weighted residuals and their autocorrelation function. ${ }^{16}$ To obtain the steady state fluorescence spectra from the samples, the fluorescence decay was measured at $2 \mathrm{~nm}$ intervals from 480 to $750 \mathrm{~nm}$. After measuring the decay at each point for 15 seconds, the emission spectrum can be obtained by plotting the maximum intensity at each wavelength.

\section{References}

1 L. J. Boucher and J. J. Katz, J. Am. Chem. Soc., 1967, 89, 1340-1345.

2 H. Liu, F. Duclairoir, B. Fleury, L. Dubois, Y. Chenavier and J.-C. Marchon, Dalt. Trans., 2009, 3793.

3 N. Alderman, L. Danos, M. C. Grossel and T. Markvart, RSC Adv., 2012, 2, 7669.

$4 \quad$ N. Alderman, L. Danos, M. C. Grossel and T. Markvart, RSC Adv., 2013, 3, 20125.

5 E. J. Nemanick, P. T. Hurley, B. S. Brunschwig and N. S. Lewis, J. Phys. Chem. B, 2006, 110, $14800-14808$.

6 R. González-Moreno, C. Sánchez-Sánchez, M. Trelka, R. Otero, A. Cossaro, A. Verdini, L. Floreano, M. Ruiz-Bermejo, A. García-Lekue, J. Á. Martín-Gago and C. Rogero, J. Phys.

Chem. C, 2011, 115, 6849-6854.

7 H. Yamashige, S. Matsuo, T. Kurisaki, R. C. C. Perera and H. Wakita, Anal. Sci., 2005, 21, 635-639.

8 S. R. Puniredd, O. Assad, T. Stelzner, S. Christiansen and H. Haick, Langmuir, 2011, 27, 4764-4771.

9 T. Toledano, R. Garrick, O. Sinai, T. Bendikov, A. E. Haj-Yahia, K. Lerman, H. Alon, C. N. Sukenik, A. Vilan, L. Kronik and D. Cahen, J. Electron Spectros. Relat. Phenomena, 2015, 204, 149-158.

10 D. K. Aswal, S. Lenfant, D. Guerin, J. V Yakhmi and D. Vuillaume, Anal. Chim. Acta, 2006, 568, 84-108.

11 H. G. Tomkins and W. A. Mc Gahan, Spectroscopic Ellipsometry and Reflectometry: A User's Guide, John Wiley \& Sons, New York, 1999.

12 C. D. Bain, E. B. Troughton, Y. T. Tao, J. Evall, G. M. Whitesides and R. G. Nuzzo, J. Am. Chem. Soc., 1989, 111, 321-335.

13 M. R. Linford and C. E. D. Chidsey, J. Am. Chem. Soc., 1993, 115, 12631-12632.

14 J. Cheng, D. B. Robinson, R. L. Cicero, T. Eberspacher, C. J. Barrelet and C. E. D. Chidsey, J. Phys. Chem. B, 2001, 105, 10900-10904. 
15 D. V. O'Connor, W. R. Ware and J. C. Andre, J. Phys. Chem., 1979, 83, 1333-1343.

16 J. R. Lakowicz, Principles of Fluorescence Spectroscopy, Springer, New York, 3rd editio., 2006. 


\section{List of Figures}

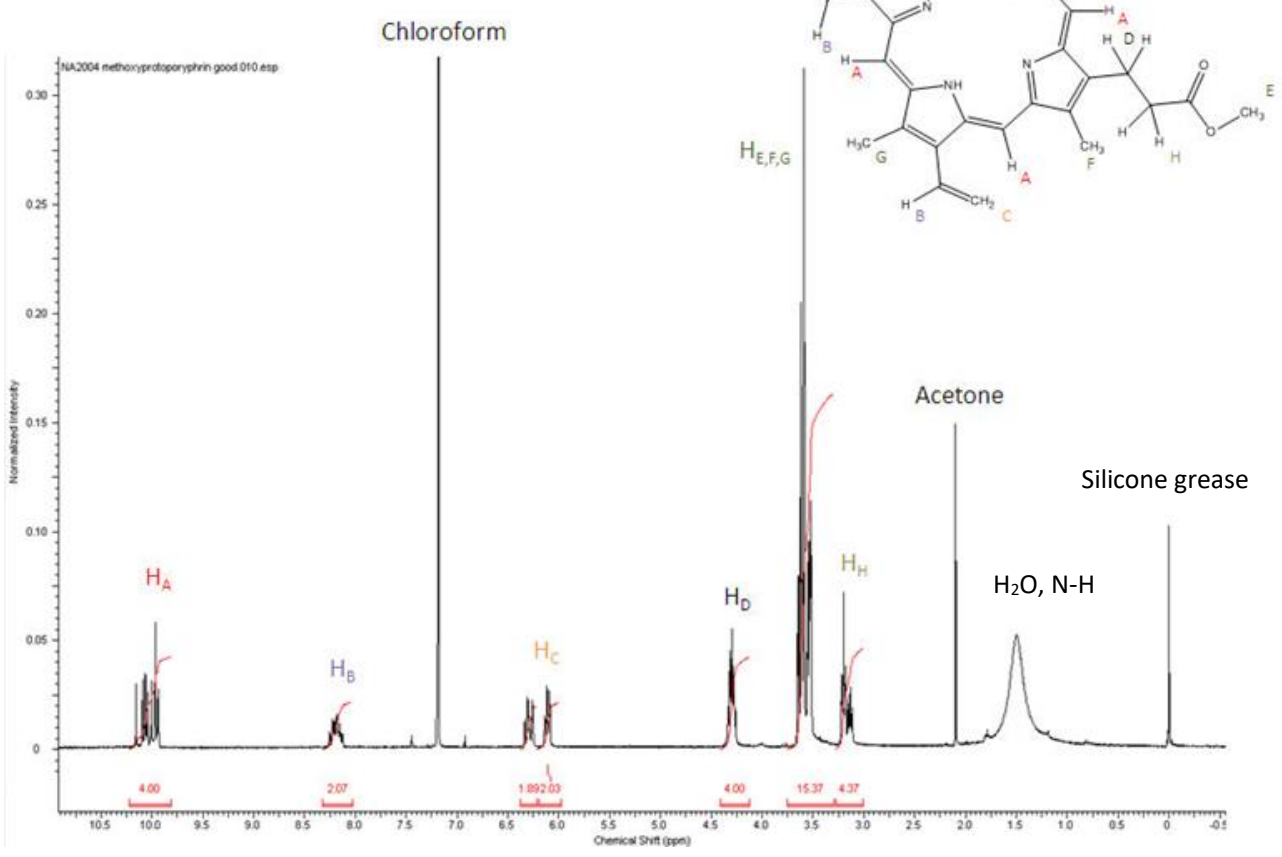

Fig. S1 ${ }^{1} \mathrm{H}$ NMR spectrum of the methoxy ester porphyrin synthesised via the acyl chloride protoporphyrin IX (PpIX-Cl).

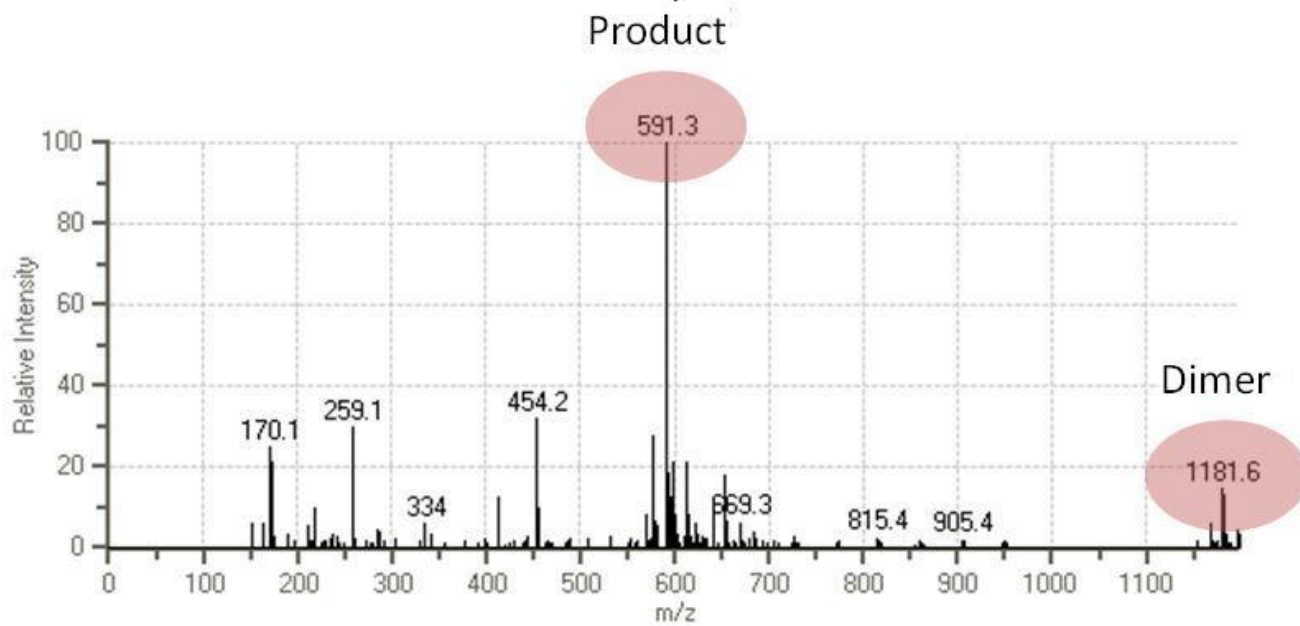

Fig. S2 Mass spectrum of the methoxy ester porphyrin synthesised via the acyl chloride protoporphyrin IX (PpIX-Cl), showing a parent ion peak for the product and a peak for the dimer of the product. 


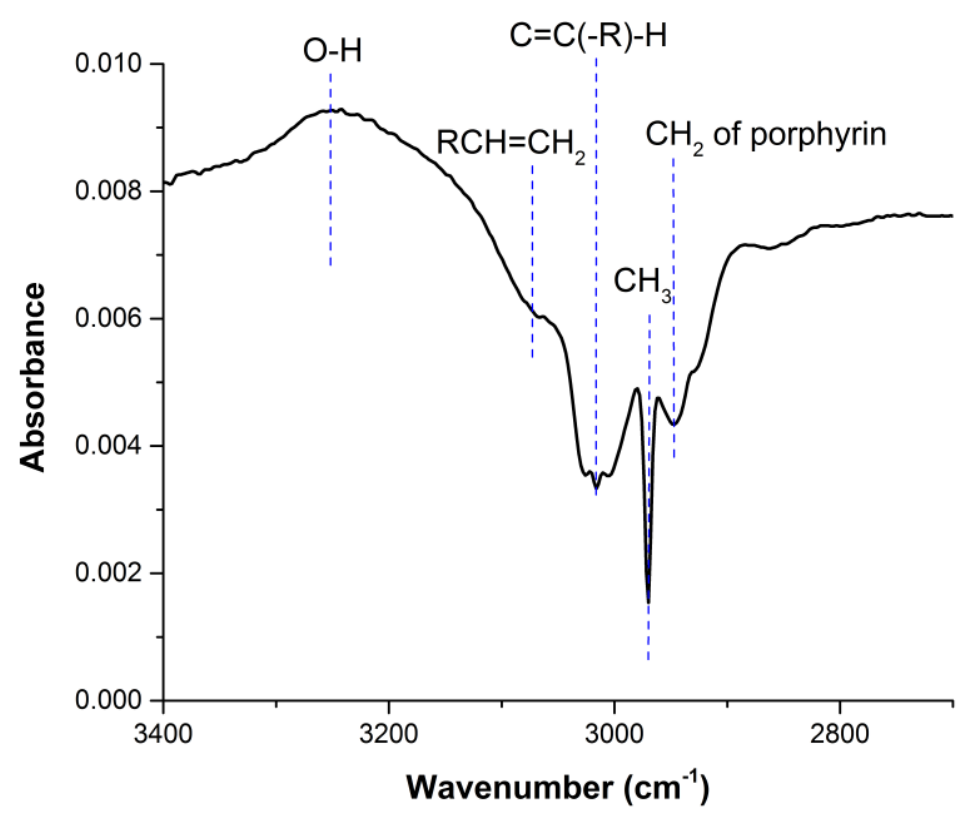

Fig. S3 FT-IR spectrum of the O-H and C-H stretching region for a 1,4 butanediol-PpIX terminated Si(111) surface.

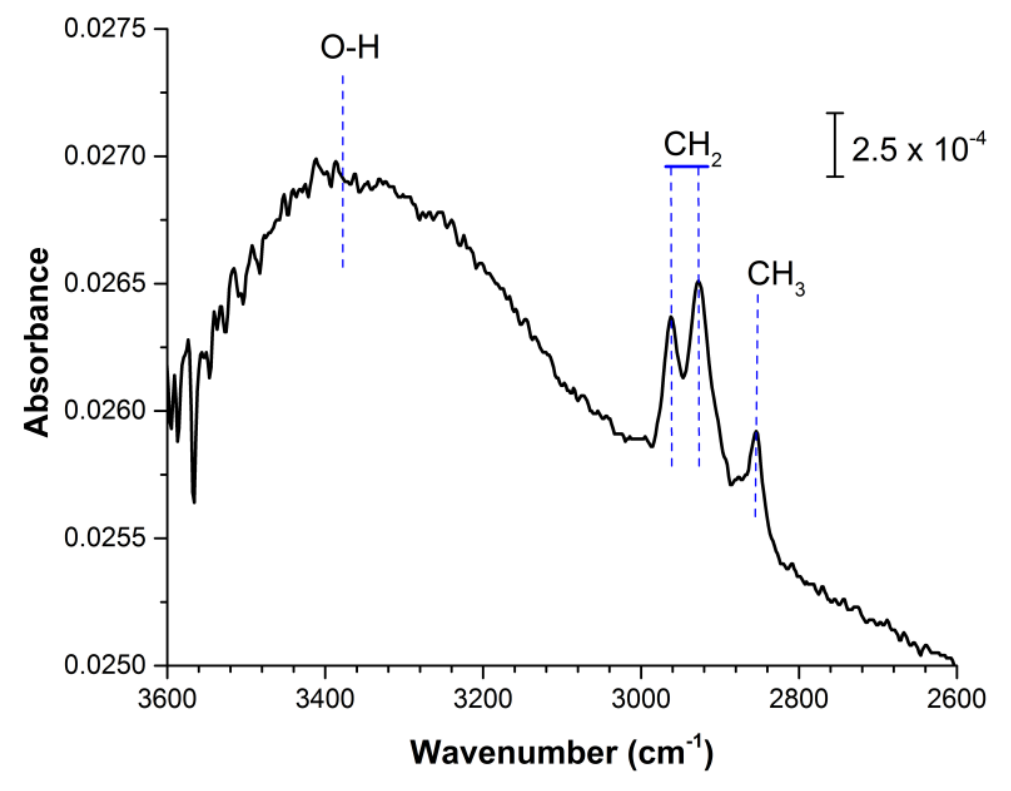

Fig. S4 FT-IR spectrum of the O-H and C-H stretching region for a 1,4 butanediol only terminated Si(111) surface. 


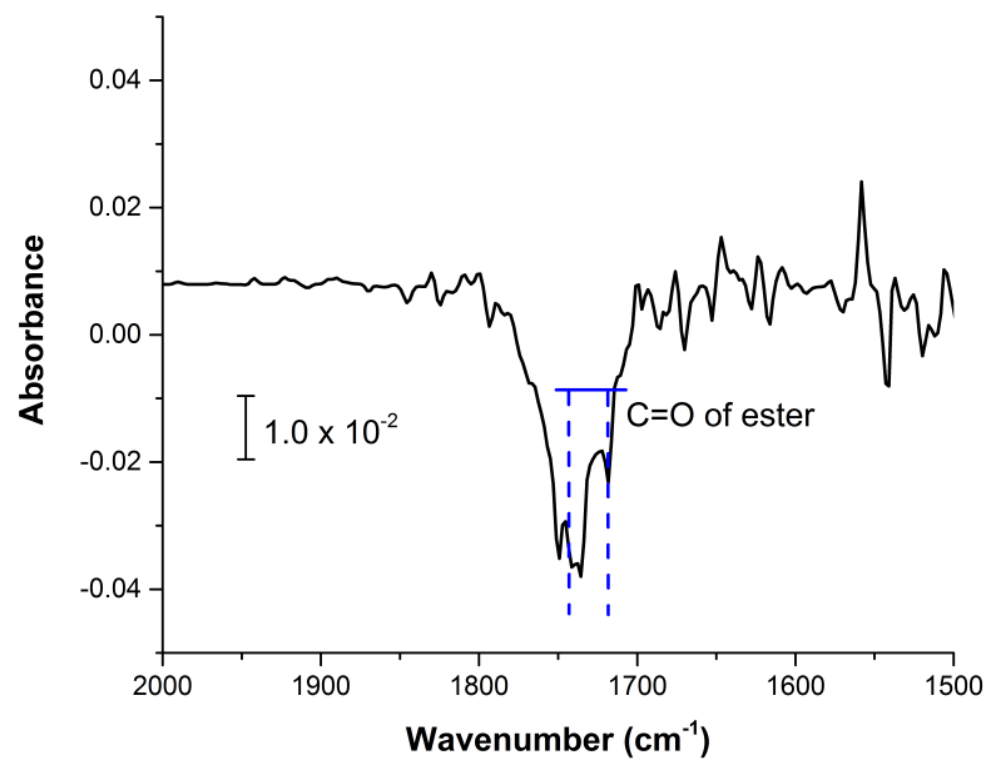

Fig. S5 FT-IR spectrum of the $\mathrm{C}=\mathrm{O}$ stretching region for a 1,4 butanediol-PpIX terminated $\mathrm{Si}(111)$ surface.

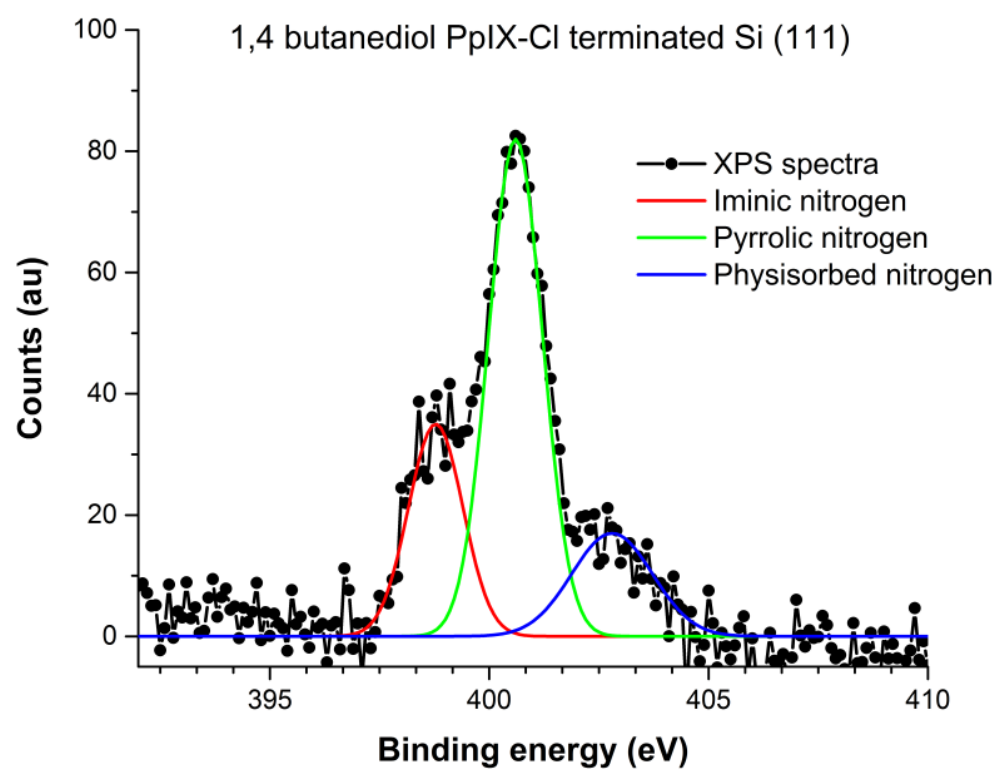

Fig. S6 High-resolution XPS spectrum in the N 1s binding region for a 1,4 butanediol-PpIX terminated $\mathrm{Si}$ (111) surface. The line + symbol indicate the experimental data and the solid lines indicate the fitted curves. 


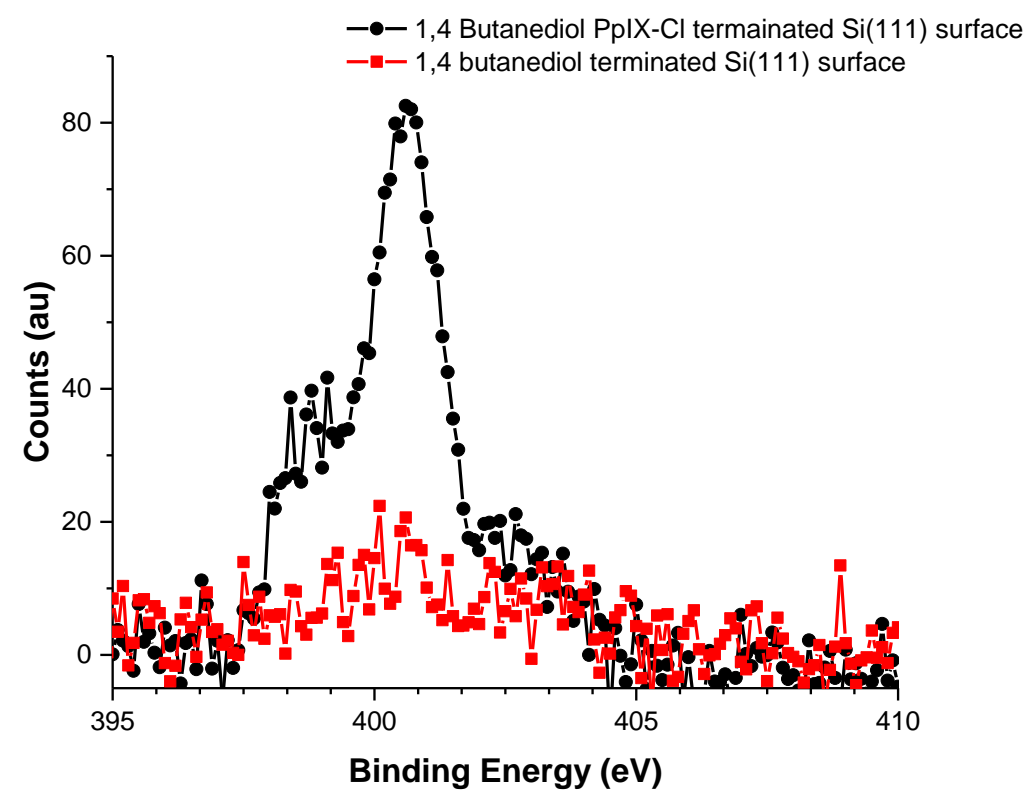

Fig. S7 High-resolution XPS spectrum in the N 1s binding region for a 1,4 butanediol-PpIX terminated $\mathrm{Si}(111)$ surface and a 1,4 butanediol only terminated $\mathrm{Si}(111)$ surface. 


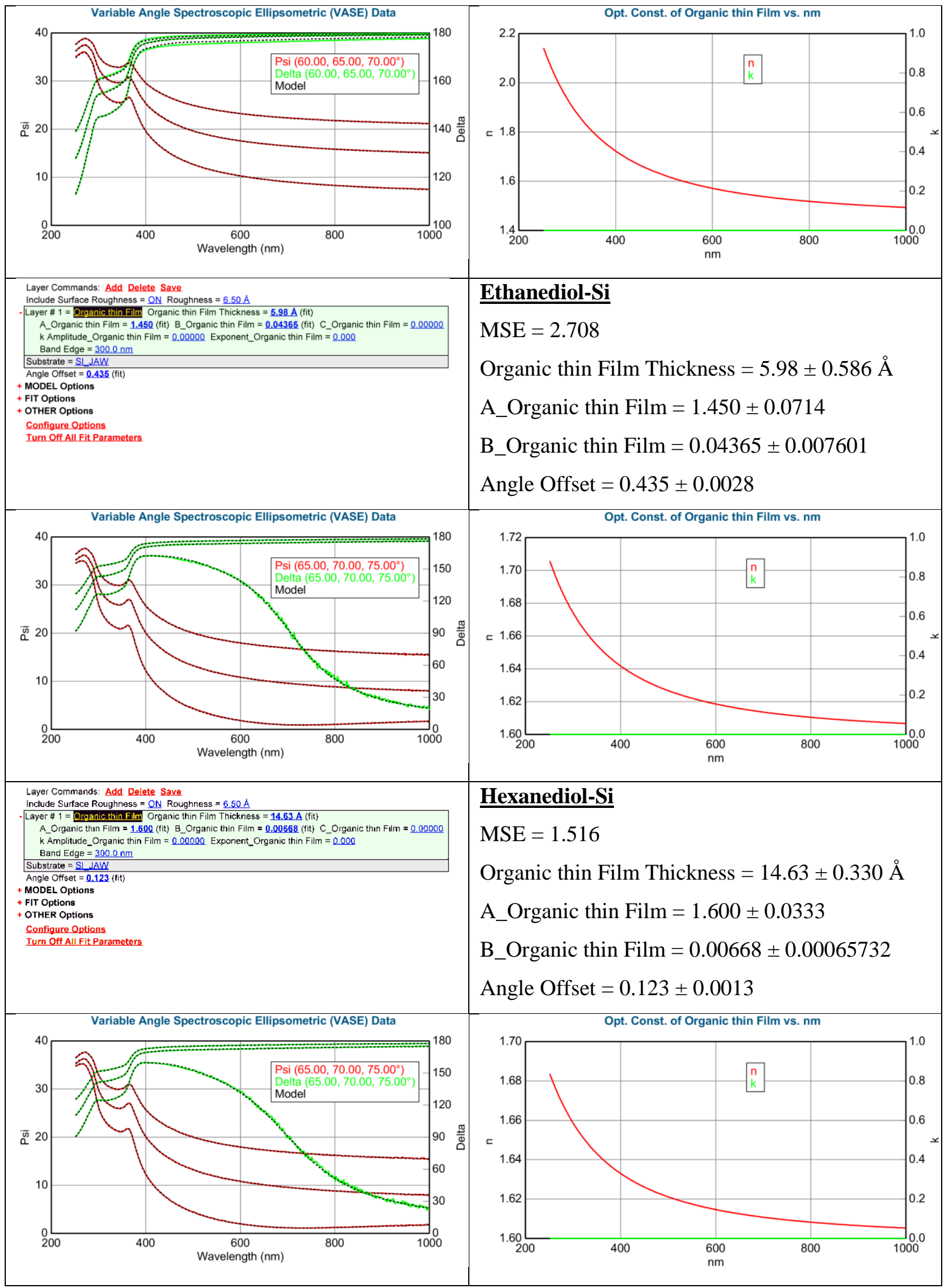




\begin{tabular}{|c|c|}
\hline 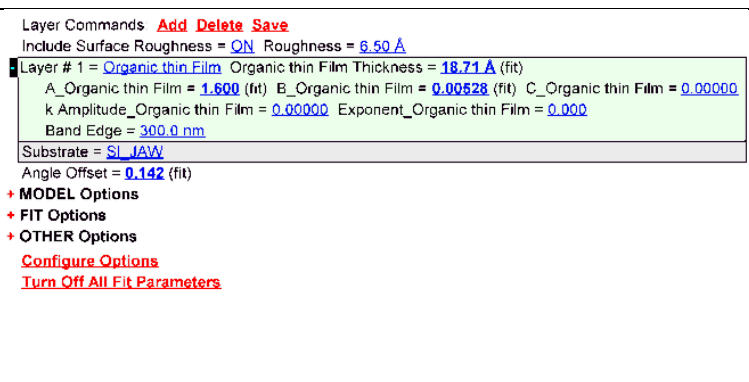 & $\begin{array}{l}\text { Decanediol-Si } \\
\text { MSE }=1.511 \\
\text { Organic thin Film Thickness }=18.71 \pm 0.310 \AA \\
\text { A_Organic thin Film }=1.600 \pm 0.0258 \\
\text { B_Organic thin Film }=0.00528 \pm 0.00059521 \\
\text { Angle Offset }=0.142 \pm 0.0013\end{array}$ \\
\hline $\begin{array}{l}\text { ig. S8 Examples of ellipsometric measurements } \\
\text { ecanediol terminated } \mathrm{Si}(111) \text { surfaces. }\end{array}$ & model fits for ethanediol, hexanediol and \\
\hline
\end{tabular}

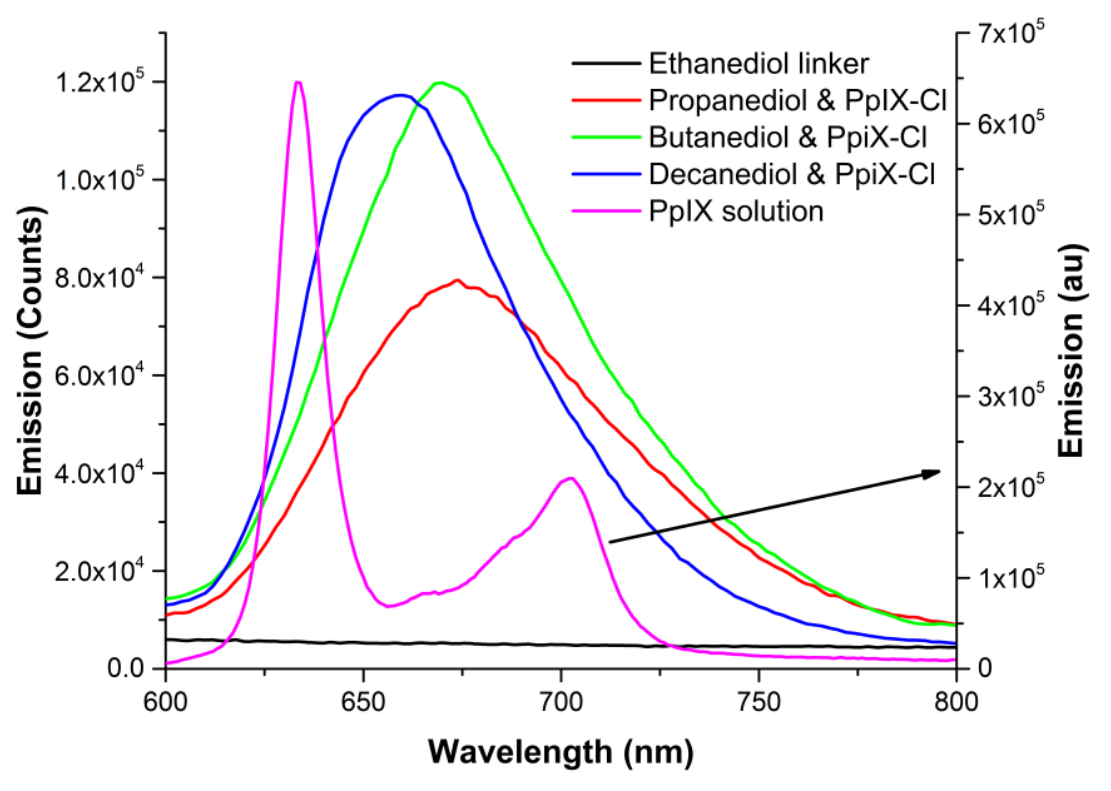

Fig. S9 Emission spectra of PpIX in solution, propanediol, butanediol and decanediol PpIX terminated $\mathrm{Si}(111)$ surfaces together with an ethanediol only terminated $\mathrm{Si}(111)$ surface. 


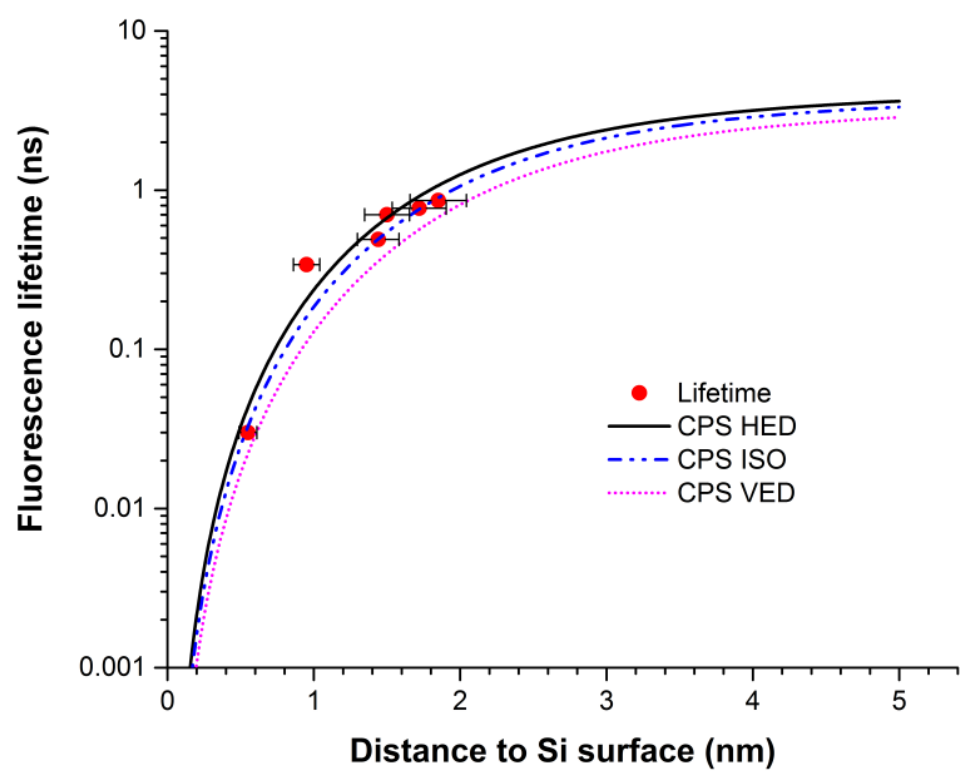

Fig. S10 Normalised rate fit of the CPS theory for horizontal (HED), isotropic (ISO) and vertical (VED) emission transition dipole moment orientations of the chromophore with respect to the surface of silicon. The experimental points (in blue) are shown together with the fitted lines. 


\section{List of Tables}

Table S1 The names and structures of the diols and protoporphyrin molecules used to produce the $\mathrm{Si}(111)$ terminated surfaces in this study.

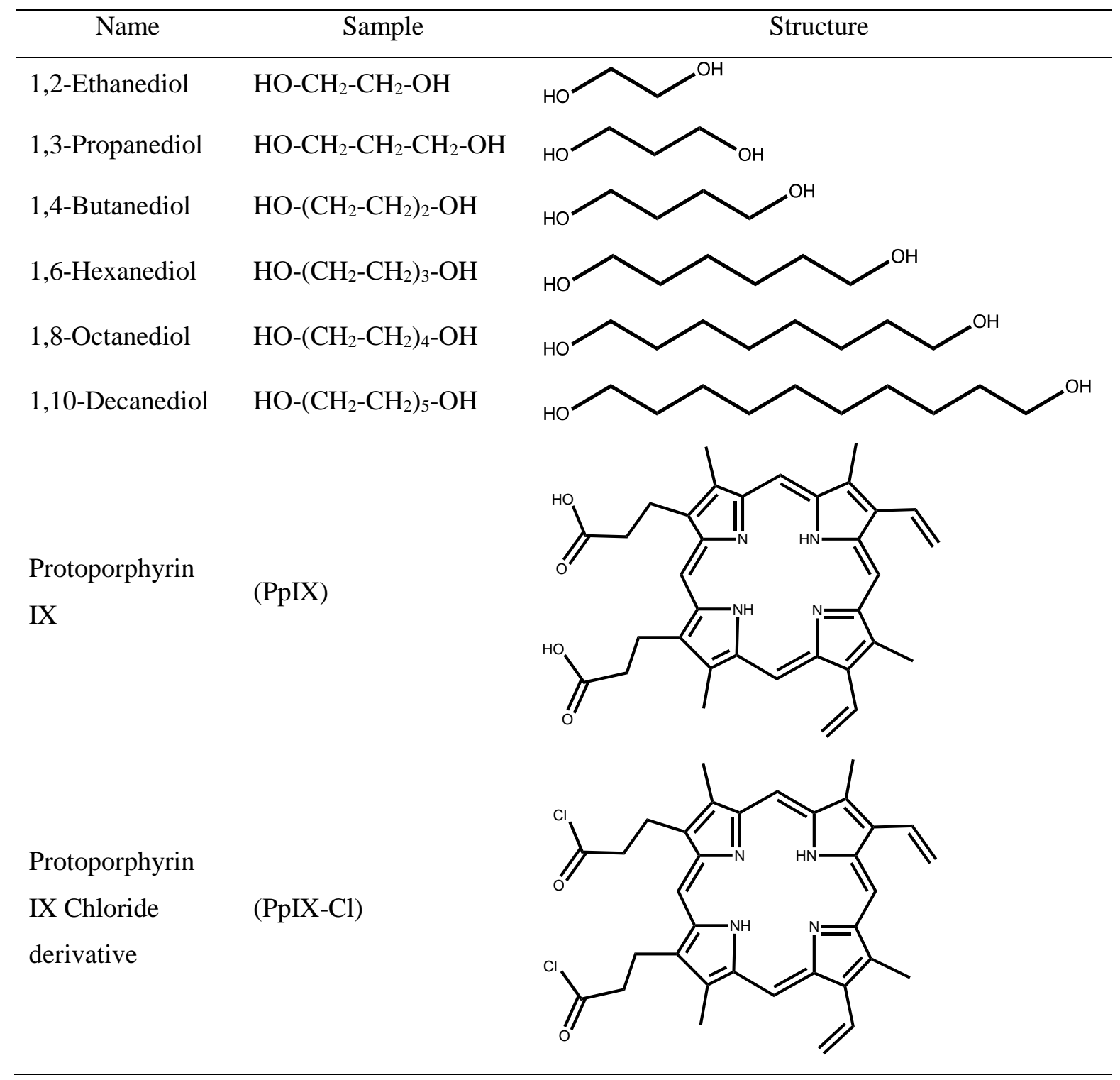


Table S2 Decay lifetimes for the various diol-PpIX terminated silicon surfaces.

\begin{tabular}{lc}
\hline Sample & Measured Lifetime (ns) \\
\hline $\mathrm{Si}(111)-\mathrm{O}-\mathrm{CH}_{2}-\mathrm{CH}_{2}-\mathrm{O}-\mathrm{PpIX}-\mathrm{Cl}$ & $0.03 \pm 0.003$ \\
$\mathrm{Si}(111)-\mathrm{O}-\mathrm{CH}_{2}-\mathrm{CH}_{2}-\mathrm{CH}_{2}-\mathrm{O}-\mathrm{PpIX}-\mathrm{Cl}$ & $0.34 \pm 0.02$ \\
$\mathrm{Si}(111)-\mathrm{O}-\left(\mathrm{CH}_{2}-\mathrm{CH}_{2}\right)_{2}-\mathrm{O}-\mathrm{PpIX}-\mathrm{Cl}$ & $0.49 \pm 0.04$ \\
$\mathrm{Si}(111)-\mathrm{O}-\left(\mathrm{CH}_{2}-\mathrm{CH}_{2}\right)_{3}-\mathrm{O}-\mathrm{PpIX}-\mathrm{Cl}$ & $0.70 \pm 0.05$ \\
$\mathrm{Si}(111)-\mathrm{O}-\left(\mathrm{CH}_{2}-\mathrm{CH}_{2}\right)_{4}-\mathrm{O}-\mathrm{PpIX}-\mathrm{Cl}$ & $0.77 \pm 0.05$ \\
$\mathrm{Si}(111)-\mathrm{O}-\left(\mathrm{CH}_{2}-\mathrm{CH}_{2}\right)_{5}-\mathrm{O}-\mathrm{PpIX}-\mathrm{Cl}$ & $0.86 \pm 0.06$ \\
\hline
\end{tabular}

